\title{
Development of agriculture based on geographic information technologies
}

\author{
Daniya Mustashkina ${ }^{1, *}$, Marat Khannanov $^{2}$, Marat Kalimullin ${ }^{2}$, and Natalia Karpova ${ }^{3}$ \\ ${ }^{1}$ Kazan Cooperative Institute (branch) Russian University of Cooperation, Kazan, Russia \\ ${ }^{2}$ Kazan State Agrarian University, Kazan, Russia \\ ${ }^{3}$ Kazan State Academy of Veterinary Medicine named after N.E. Bauman, Kazan, Russia
}

\begin{abstract}
The article discusses the need to use digital technologies that can be used in agriculture not only for financial management and tracking of economic operations, but farmers began to use them to monitor sowings, in agricultural production. One of the most promising directions of improving the management efficiency of agricultural production is associated with the use of geographic information technologies based on information systems, especially in risky agriculture. A large number of vehicles, a large number of personnel employed in agriculture determine the need to develop new management methods in agricultural production. GIS technology allows economic sector employees to conduct a comparative analysis of planned and actual data automatically calculated by the formation of working hours, reports and certificates.
\end{abstract}

\section{Introduction}

A geographic information system is a means of ensuring security by visual representation of spatial characteristic information, software and hardware platforms, as well as detailed analytical information. Historically, geographic information systems began to develop in the late 1950s of the last century. The United States, Canada, and Western Europe contributed to the development of geographic information systems in the 1950s and 1960s, while Russia became involved in the global process of creation and development of GIS technologies only in the mid-eighties.

The history of GIS development has several periods. The main features of GIS research were marked in the 50s and 60s, the first major projects were created and GIS was introduced. One of these important projects was the development of the Canadian geographic information system, a large-scale GIS has been preserved and is still used today. Roger Tomlinson from Canada made a great contribution to the development of geoinformation technologies, under his leadership, many conceptual and technical solutions were developed and implemented.

The original objective of this GIS was to classify and map Canadian land resources. An interesting fact is that the results of the first GIS were presented in the form of tables, not cartographic materials, not summary studies.

\footnotetext{
* Corresponding author: daniya56@ mail.ru
} 
While Russia joined the global process of creating and developing GIS technologies only in the mid-eighties. The GIS Association was established in 1995 in the Soviet Union, as a non-governmental and non-profit public organization, they did not have time to become widespread, but oil and gas companies and telecommunications systems of foreign manufacturers showed interest in the early 90s. The idea was supported by the Russian government and was included in the federal target program "Electronic Russia", which was in effect in 2002-2010, aimed at improving the quality and efficiency of the provision of state and municipal services.

In 2006, work was carried out on the development of a draft concept for the formation of a spatial data infrastructure as an element of national information resources, an important step was taken in the field of GIS technologies, the draft concept was approved by the Government of the Russian Federation, which provided for a complete transition to digital technologies in the acquisition and use of spatial data. According to this concept, a country should be a hierarchical and geographically distributed system for collecting, processing, storing and providing basic spatial data and a data method. In addition, GIS technology provides users with remote access to a digital spatial database and the data contained in it [1, p. 116].

At the present stage, GIS is actively used not only in the oil and gas, telecommunication industries, but also has found active application in agricultural production, forestry and other areas of human activity. To this date, GIS is one of the most promising technologies in many organizations engaged in production activities, as a tool for improving business processes of enterprises.

\section{Materials and method}

At present, agriculture is associated with a large number of equipment, production and the number of employees. Considering seasonal and natural work conditions, not production losses and risks.

Today, a more effective growth in the development of agro-industrial enterprises is of a strategic nature, they strengthen the confidence of agricultural producers, their competitive positions in the world market, give them the opportunity to improve the changes in the external environment, create conditions for management.

In agriculture, they request objective information about the extent and condition of agricultural land. A large amount of spatial and attributed information can be processed and analyzed qualitatively only with the help of special software that takes into account spatial references and special [2, p. 69] field information.

Information management, based on geoinformation technologies, plays an important role in the planning of agricultural operations. Agricultural planning includes the following types of work: assessment of potential and efficiency of the use of human resources and land resources. Large-scale implementation of computer technologies in agriculture is observed in the United States, Europe and Russia.

Management information, based on geoinformation technologies, played an important role in the planning of agricultural operations. If the plan includes the following activities and the assessment of the potential efficiency of the use of human and land resources $[3, p$. 26].

The technological leap in agriculture is in high demand due to the growth of the world's total population, the growing well-being of the inhabitants of many countries, as well as the growing demand for high-quality organic food. Traditional agricultural products and technologies, many countries have exhausted their development potential: lack of land and water resources, accelerated soil degradation, and high use of mineral fertilizers and other agrochemicals have prevented them from further increase in their production. 
Agricultural innovations are new plant varieties, fertilizers and animal and plant protection products, modern equipment, methods of prevention and treatment of animals, animal varieties and poultry hybrids, technologies, organizational forms and production resources.

Providing innovative formation [4, p. 142] of agro-industrial enterprises, in the initial turn, it is necessary to develop an innovative and investment model of the definition of an agricultural enterprise, in the context of the formation of agricultural territories, considering regional characteristics of agricultural production and the possibility of the natural resource potential of agricultural territories.

As Europe and the United States have already noted, a geographic information system for agricultural producers is an essential component of an integrated economic management system. In Russia, this situation is associated with the information system of the AllRussian Institute of Agricultural and Aerial Photogeological Surveys (VISHAGI), which has created a large number of land-cadastral, soil, geographical plant materials and agricultural maps. According to the specialists of the Regional Department of the Institute, reliable information was collected on the availability of land plots in each region, in each territory, and in each land user, which contained comprehensive data on land type, assessment of arable land quality, exact boundaries of the plots that were maintained since the Soviet period. As the industry continues to stagnate, and farmers do not have highquality cartographic materials, the level of information training of agricultural specialists wants to remain at the highest level. The cartographic material present at the enterprise is often incomplete and largely outdated and does not meet the modern requirements presented on a cartographic basis. Not all farms have land management materials compiled by cadastral plans. Having inadequate information about the state of the fields [5, p. 26] complicates making informed decisions about the cultivation of relevant crops and the use of agricultural technology.

For a long time, the agricultural business was unattractive to investors due to the long production cycle, natural risks of planting, crop loss, harvesting and storage conditions, lack of productivity and innovation.

Recently, to improve the efficiency of agricultural production management, farmers use geoinformation systems to solve the following tasks:

- Collect, classify and combine all agricultural transaction data with reference to geographical location;

- Single storage with statistics;

- Creation of vector maps of territories, which allows to quickly and cost-effectively conduct an inventory of assets and structural data on various media, etc.

For more effective use of agronomic geoinformation systems, it is necessary to include multi-layer electronic maps of farms and a database of field historical attributes containing information on all types of agricultural activities. This is mandatory and includes the average layer pressure, information about steep slopes, their locations, microclimate, ground water level, fertilizer content in the soil, etc.

The main database, which includes all possible data images, is combined with the electronic map layers. It forms an electronic map database with layers containing various types of data.

The use arises from the hydrological network, the trench-beam complex, the addition of the road network and other objects. Objects in the digital map database include notification of acreage, information about the soil state, etc.

The electronic map contains detailed information from satellite geodetic surveys and is used to solve complex analyses in agriculture. This method allows to get detailed information about the general territoriality of agricultural enterprises and administrative 
areas. Determining the field configuration, the volume of the agricultural area and their condition at the time of shooting.

\section{Results}

The GLONASS satellite system operates today in agriculture in the cultivation of grain crops. The use of GLONASS technology is divided into guidance, data review, and variable tempo systems.

The navigation satellite system is the most important function of the software used, it allows to create an electronic mapping of fields by soil fertility. Thanks to the electronic field map, the entire range of sowing operations on the cultivated areas is controlled. The sowing equipment is provided with a satellite system that allows to grow high-quality crops and improve the processes of agricultural production.

The system allows to reduce costs at the production stages, and increase the agriculture profit and profitability [6, p. 42].

The efficiency of the work of farmers, allows to plan the schedules of sowing and harvesting operations, due to satellite data, high-quality mapping of fields is created, which are made in real time, thanks to this, specialists can determine the state of the soil, arable land and vacant land. To monitor the condition and development of grain crops, the dynamics of their development, analyze the productivity of land and other agricultural activities

According to the images taken from space, the presence of an elementary soil structure is checked, the determination of the components of the territories that belong to them is carried out. The figure shows the system of GIS technologies application in agriculture

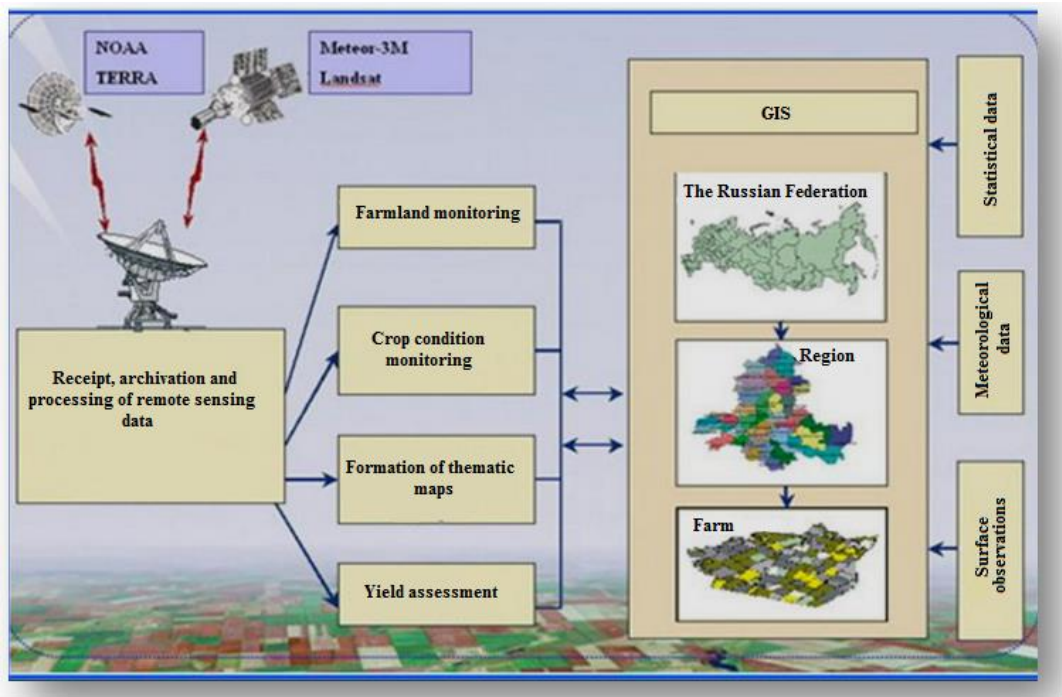

Fig. 1. Scheme of the sectoral monitoring system of agricultural resources.

With the help of GIS, it is easy to analyze all the agricultural processes performed and display the information obtained in the form of maps, tables and graphs. It consider provision of from the website, getting food from the website, and current sales. In this case, the data can be collected from the control center or the current electronic scale. The use of pesticides and fertilizers should be considered. Determine the seed consumption during sowing. When using a parallel drive system to minimize the overlap of crop strips, the consumption of seeds and fertilizers can be reduced. 
To predict the yield formed on the monitoring of the state of crops, considering the influence of natural and climatic conditions. The proposed technology allows to track the formation of crops, the dynamics of growth conditions, determines the timing of development and the optimal timing of the start of harvesting, maintaining minimum and maximum yield levels for economic analysis in specific conditions.

Decisions are made on a differentiated approach to production [7, p. 12], considering the forecasts obtained at different sites, including costs and possible recoverable profit. On the other hand, possible losses can be analyzed based on the potential of crops in barren lands. Computer monitoring systems are used to more accurately determine the level of yield in farmers' fields.

Data analysis in the system is performed using cartographic analysis, which allows to obtain spatial definitions of data that increases or decreases performance. Forecasting productivity and estimating losses [8, p. 333], the manager will be able to calculate the optimal prices for the purchase of equipment and raw materials needed by the company in the future, and determine the purchase price of agricultural products. From the point of view of the use of hydroconversion technology, it does not stand aside. Equipment of agricultural enterprises. It comprises the following:

- Set a schedule for the use of equipment and its maintenance;

- Analyze the volume of equipment, used to move them, processing area, calculate the mileage, fuel and lubricants;

- Determine the optimal route of equipment movement from the base to the processing site;

- Determining the optimal route for transporting crops to the receiving point, considering the distance between the field and the point of agricultural product delivery on a digital map, as well as monitoring the speed of equipment movement during field work;

- Create a registration list of tractor drivers and drivers and a track list of vehicles.

Use of GIS technologies, the agronomist's workplace allows to record the history of the field by yield, fertilizers, and the use of protective equipment. It plans fertilizer introduction, considering individual characteristics of the field. Provides information for evaluating the quality of work [9, p. 193] and making recommendations for planning. The system used allows employees of the economic sector to conduct a comparative analysis of planned and actual data, automatically calculate working hours and generate reports.

When managing agricultural production using risky farming, it is necessary to constantly monitor these areas [10, p. 79], the conditions of crop formation, as well as the introduction of agricultural technologies and agrochemical measures, which are very important in agriculture. GIS technologies are needed to improve livestock production processes at low cost and solve pasture problems where natural vegetation is scarce.

The implementation of a GIS application has a payback period depending on the size of the implemented system, as practice shows, the results from the implementation of the system are clearly visible at the end of the first quarter of application. Respectively, the reduction of costs and efficiency of the use of available resources, competitiveness increases along with the profitability of the business, so the creation of an information system for decision-making based on GIS technology can improve the overall efficiency of agricultural production by urgent provision of analysis of information about the parameters needed to make more effective and timely management decisions. The technology of geoinformation systems is used - one of the leaders of agribusiness, the Prodimex holding. Today the holding employs more than 17 thousand people, with more than 800 thousand hectares of land located in the eight best agricultural areas. Prodimex is one of the five largest sugar producers. Professional methods consider the peculiarities of natural and climatic conditions in each region, the optimal choice of seeds, determine the exact dose of mineral fertilizers and protective agents. 
In crop yield management, farmers use satellite and laboratory data to obtain accurate characteristics of all areas of the field, so seeds and fertilizers are not applied "by eye", but by accurately resource calculation. This allows to reduce losses, optimize costs, reduce the cost of production and increase labor productivity. All this gives companies implementing high-precision agricultural technologies a serious competitive advantage in the market. According to the field vegetation index, the company evaluates the state of the crop and creates a task map for the sower at the time of fertilization. Depending on the conditions of the plant, they are introduced according to different criteria. This allows to use fertilizers more efficiently. Delete the test field and plot the yield based on this analysis.

\section{Conclusions}

At present time, the success of agriculture, stability in the fight for competition and maturation planning are largely due to the availability of various information and the ability to quickly view and analyze it. According to the data provided, about $80-90 \%$ of all information consists of geographical data, diverse information about objects, phenomena and processes. The use of data from the coordination level is characterized by one of the most dynamically developing areas of the computer software market - the technology of geographic information systems. The geographic information system is the best platform for integrated solutions in the field of agriculture. Forming a digital model of the entire production cycle and the interconnected links of the value chain, it automates the maximum number of agricultural processes and plans the work schedule with mathematical accuracy, urgent measures are taken to prevent losses in case of a fixed threat, possible harvests, production costs and profits are calculated.

\section{References}

1. A.G. Duplenko, Young scientist, 9 (89), 115-117 (2015) URL: https://moluch.ru/archive/89/18321/

2. N.A. Markova, D.S. Nardin, Electronic scientific and methodological Journal of the Omsk State Agrarian University, 1(4) (2016) URL http://ejournal.omgau.ru/index.php/2016-god/4/25-statya-2016-1/242-00069. - ISSN 24134066

3. T.S. Zagidullina, N.N. Zhilina, M.R. Magdeeva, Economics and Management: problems, solutions, 4(7), 25-29 (2018)

4. L.G. Kirillova, V.V. Orlova, Innovative activity of enterprises and forms of state support, Actual problems of the economy of modern Russia. Collection of materials of All-Russian (national) science and practical conf., Yoshkar-Ola: Mari State University, 141-143 (2019)

5. D.A. Mustashkina, Russian entrepreneurship, 10, 24-27 (2006)

6. R. Shakirova, A. Khasanova, G. Sabirova, D.A. Mustashkina, Concept and significance of state financial control, In the collection: days of student science, Collection of scientific papers of the International Student Conference, 83-85 (2018)

7. Ya.F. Nashirvanova, E.S. Makarova, E.Yu. Elesin, Economics and Management: problems, solutions. 1(9 (105)), 10-16 (2020)

8. D.A. Mustashkina, M.M. Khannanov, Italian Science Review, 4(13), 333 (2014)

9. D.A. Mustashkina, Ch.S. Hayaleeva, N.V. Karpova, Italian Science Review, 1(22), 55 (2015) 
10. D.R. Vakhitov, R.A. Latypov, Directions of digitalization of the world and domestic economy, In the collection: Transformation of the national socio-economic system, Materials of the II International Scientific and Practical Conference, Moscow, 192-196 (2020)

11. M.R. Shamsutdinova, M.A. Loseva, Economics and Management: problems, solutions, 12, 78-82 (2012) 